\title{
COVID-19 Y RESPONSABILIDAD CIVIL MÉDICA: DESAFÍOS DE UNA ENFERMEDAD DESCONOCIDA QUE DEVINO EN PANDEMIA
}

\author{
Hugo Cárdenas Villarreal ${ }^{1}$, Manuel Antonio Pérez Saavedra²
}

Resumen: La emergencia sanitaria provocada por el coronavirus evidencia que los regímenes de responsabilidad deben ser capaces de diferenciar los instrumentos conceptuales disponibles para lidiar con una enfermedad nueva que, además, devino en pandemia. Este trabajo postula que, tratándose de enfermedades nuevas, los principios de la responsabilidad por culpa evitarán que los prestadores médicos sean condenados por hechos o circunstancias que no se hubieran podido prever o evitar según el estado de los conocimientos de la ciencia. Además, en cuanto al problema de salud pública, todo juicio de responsabilidad deberá tomar en cuenta los cambios que se producirán en la lex artis médica, y diferenciar la eventual responsabilidad de los prestadores de salud de aquella que corresponda a la autoridad encargada de controlar los efectos de la pandemia.

Palabras clave: responsabilidad médica, covid-19, lex artis, riesgos del desarrollo, pérdida de la chance, falta de servicio, salud pública

\section{Covid-19 and medical liability: challenges of an unknown disease that became a pandemic}

\begin{abstract}
The coronavirus health-emergency shows that liability schemes need to discriminate the conceptual instruments available to address a new disease that, additionally, has become a pandemic. This article argues that, regarding new diseases, a fault-based liability schemes prevents health providers from being held liable for consequences that could not have been foreseen or avoided according to the state of knowledge of science. Besides, regarding the public health problem, any liability judgment must take into account changes to the medical lex artis; distinguishing also the eventual liability of health providers from the one that belongs to the authority in charge of the response to the pandemic.
\end{abstract}

Key words: Medical liability, covid-19, lex artis, development risk defence, loss of a chance, lack of service, public health

Covid-19 e responsabilidade civil médica: desafios de uma enfermidade desconhecida que se transformou em pandemia

Resumo: A emergência sanitária provocada pelo corona vírus evidencia que os regimes de responsabilidade devem ser capazes de diferenciar os instrumentos conceituais disponíveis para lidar com uma enfermidade nova que, além disto, se transformou em pandemia. Este trabalho postula que, tratando-se de enfermidades novas, os princípios de responsabilidade por culpa evitarão que os prestadores médicos sejam condenados por fatos ou circunstancias que náo se podia prever ou evitar segundo o estado dos conhecimentos da ciência. Além disto, quanto ao problema de saúde pública, todo juízo de responsabilidade deverá ter em conta as mudanças que se produzirão na lex artis médica e diferenciar a eventual responsabilidade dos prestadores de saúde da que corresponda à autoridade encarregada de controlar os efeitos da pandemia.

Palavras chave: responsabilidade médica, covid-19, lex artis, riscos de desenvolvimento, perda de oportunidade, falta de serviço, saúde pública

\footnotetext{
${ }^{1}$ Departamento de Derecho Privado, Facultad de Derecho, Universidad de Chile, Chile. ORCID: https://orcid.org/0000-0002-0262-922X Correspondencia: hcardenas@derecho.uchile.cl

${ }^{2}$ Facultad de Derecho, Universidad de Chile, Chile. ORCID: https://orcid.org/0000-0002-7212-4163
} 
A casi seis meses de que se haya declarado la alerta sanitaria, Chile registra 319.493 casos confirmados de covid-19, al tiempo que 7.069 personas han muerto a causa del coronavirus(1). Y, si bien en los primeros meses los números avalaban la gestión de la autoridad sanitaria, al mes de julio de 2020 el país lidera los índices de contagios por millón de habitantes, por lo que se ha empezado a plantear el problema de la responsabilidad.

La relación entre prestaciones médicas y responsabilidad se intensifica cuando los profesionales de la salud se enfrentan a una enfermedad nueva. Más aún si esa enfermedad deviene en pandemia. Ambos factores, que implican dudas cognitivas y sobrecarga de trabajo, inciden significativamente en la toma de decisiones, pudiendo desencadenar perjuicios en los pacientes.

Desde luego, la responsabilidad médico-sanitaria no está supeditada al éxito o fracaso de un tratamiento. Jurídicamente, lo relevante es la conducta desplegada y el daño solo es un indicio de que pudo haber una conducta negligente(2,3). Para que exista derecho a indemnización es necesario acreditar una conducta negligente $y$, para esto, no basta constatar un daño. Por eso, en materia de responsabilidad, la pregunta clave apunta al estándar de cuidado que deben seguir los establecimientos y profesionales de salud. Hoy, en tiempos de pandemia, esta pregunta se hace más urgente.

En este artículo analizaremos qué instrumentos conceptuales dispone el derecho de la responsabilidad para lidiar con una enfermedad nueva que deviene en pandemia. Tomando como referencia la situación del covid-19, ofreceremos una lectura de la responsabilidad médica que incorpore consideraciones propias de la salud pública. Defenderemos el argumento de que no debe haber responsabilidad por daños que se deriven de hechos o circunstancias que no se hubieran podido prever o evitar según el estado de los conocimientos de la ciencia, salvo que los mismos hayan sido causados por productos sanitarios defectuosos. Respecto del control de la pandemia, sostendremos que el juicio de responsabilidad que se haga deberá tomar en cuenta la alteración que sufrirá la lex artis médica, así como la eficacia de los actos de autoridad.

\section{Herramientas normativas para tratar enferme- dades desconocidas}

El tratamiento de los efectos nocivos de enfermedades "desconocidas" no es nuevo ni para la medicina ni para el Derecho. Un ejemplo fue la aparición del VIH. Múltiples contagios se produjeron mediante transfusiones de sangre antes de que se descubriera la forma de transmisión del virus, a partir de los inicios de los ańos ochenta.

Cuando existen enfermedades desconocidas, como la generada por la acción del VIH o el SARS CoV-2, la ciencia comienza una carrera por identificar y controlar la amenaza. Muchas veces ello implicará identificar la estructura y la forma de propagación de la enfermedad para, sobre esa base, implementar las estrategias de prevención y tratamiento, sobre todo en la fase inicial de este proceso, profesionales de la salud indudablemente ejecutarán y omitirán acciones que generarán dańos a las personas y que, por lo mismo, plantean la pregunta por la responsabilidad.

En el caso de los contagios de VIH por transfusiones de sangre, Francia optó por poner la reparación de esos daños a cargo del Estado. En efecto, debido a la conmoción social que generaron esos casos y a las dificultades que supondría su juzgamiento por tribunales ordinarios, se ordenó la reparación de todas las víctimas mediante la Ley $\mathrm{N}^{\circ} 91-1406$ de 31 de diciembre de 1991(4:157). Lo importante del ejemplo, aparte de mostrar que el recurso a fondos públicos es una opción, es que invita a preguntarnos por los otros instrumentos conceptuales disponibles. En especial, por los instrumentos conceptuales que puede aportar el derecho de daños.

En el contexto descrito, cobra especial importancia que analicemos el principio rector de la responsabilidad civil médica, así como el endurecimiento que ha tenido en los últimos años el régimen de responsabilidad por los daños asociados a medicamentos y a otros productos sanitarios defectuosos. 


\section{La responsabilidad por culpa como principio rector de la responsabilidad médica}

El conocimiento técnico y científico que se tiene de enfermedades "nuevas" es, normalmente, muy precario. Las incertezas que existen respecto de ellas, como ocurre tratándose del coronavirus, acrecienta las posibilidades de que, con el tiempo y el desarrollo de las investigaciones, se descubra que algunas acciones u omisiones médicas no fueron acertadas respecto del tratamiento de esa enfermedad.

En términos de responsabilidad civil o patrimonial existen dos regímenes básicos que se diferencian por la noción de "culpa". Mientras en los regímenes estrictos u objetivos se responde por los daños que se sigan causalmente de la acción, en los regímenes subjetivos solo se responderá si la conducta de quién causa el daño es merecedora de un juicio negativo de valor. La conducta puede ser intencional (dolo o culpa intencional) o puede suponer la infracción no intencional de una norma de cuidado (negligencia, culpa no intencional, o simplemente culpa). Y para determinar si una conducta es negligente se recurre al criterio de la previsibilidad. Así, será negligente quien actúa sin prever, debiendo hacerlo (según el parámetro de una persona razonable), que sus acciones u omisiones tendrán consecuencias negativas (5:75 y ss.).

Por lo anterior, ante la pregunta por la responsabilidad de los prestadores de salud por el riesgo de actuar frente a una enfermedad desconocida, el Derecho les ofrece una vía natural de protección, al sujetar su responsabilidad a un régimen de responsabilidad por culpa. Ello quiere decir que, en el contexto del tratamiento de personas con covid-19, los prestadores de salud que, con la intención de tratar a los pacientes, causen daños que no eran previsibles al momento que ejecutaron su acción, serán exonerados de responsabilidad: precisamente porque su acción u omisión no podrá ser considerada culpable.

El razonamiento recién referido fue recogido en el artículo 41 de la Ley No19.966, que regula la responsabilidad de los órganos del Estado que prestan servicios médico-sanitarios, en los siguientes términos: "[n]o serán indemnizables los daños que se deriven de hechos o circunstancias que no se hubieran podido prever o evitar según el estado de los conocimientos de la ciencia o de la técnica existentes en el momento de producirse aquéllos".

Dado que el Título III de la Ley $\mathrm{N}^{\circ} 19.966$ introduce un régimen subjetivo de responsabilidad por falta de servicio (por culpa o negligencia de los órganos del Estado), se podría pensar que la regla del artículo 41 simplemente reafirma una consecuencia de aquel régimen. Efectivamente, se reitera la norma de responsabilidad por culpa que dispone el artículo 38 de la referida ley. Por lo mismo, en principio, el artículo 41 sería una disposición inocua desde el punto de vista de la responsabilidad por las acciones u omisiones en que puedan incurrir quienes intervengan en el tratamiento de enfermedades nuevas como el covid-19.

La reiteración se explica por el contexto en que se gestó la Ley $\mathrm{N}^{\circ} 19.966$, época en que se discutía si el régimen de responsabilidad del Estado era objetivo o subjetivo. En nuestra opinión, el artículo 41 vino a reafirmar el carácter subjetivo del régimen de responsabilidad consagrado en el artículo 38, al evitar que el concepto de "falta de servicio" que emplea dicha disposición pudiese ser leído en clave objetiva, como había ocurrido con el régimen español de responsabilidad de la administración que se estaba tomando como modelo(2:\$2.I).

En paralelo, algún autor ha sugerido que la regla del artículo 41 importaría una flexibilización probatoria del caso fortuito. A diferencia del régimen general, que exige para el caso fortuito la concurrencia copulativa de la imprevisibilidad y la irresistibilidad del evento dañoso, el artículo 41 permitiría la exoneración de la responsabilidad con la acreditación de una cualquiera de esas características(6). Esta última lectura, aun siendo plausible, no ha tenido prácticamente ningún impacto en la jurisprudencia de los tribunales ${ }^{3}$.

No obstante lo anterior, dado que la norma contenida en el artículo 41 está redactada en terminología propia de la noción de los riesgos del desarrollo $(7,8)$, creemos que tendrá una importante aplicación a propósito de la contingencia ocasio-

\footnotetext{
${ }^{3}$ En este sentido, el único fallo que hemos encontrado es $1^{\circ}$ Juzgado Civil de Rancagua, Rol C-3383-2018.
} 
nada por la enfermedad asociada al SARS CoV-2. $\mathrm{Y}$ es que, como veremos enseguida respecto de los daños producidos por productos sanitarios defectuosos, una relativamente reciente legislación ha introducido en el Código Sanitario un régimen de responsabilidad estricta u objetiva, prohibiendo alegar la excusa exoneratoria fundada en la noción de los riesgos del desarrollo, al tiempo que dispuso que la responsabilidad de la Central de Abastecimiento del Sistema Nacional de Servicios de Salud (CENABAST) se regirá por las normas del Título III de la ley No19.966.

La supresión de la excusa liberatoria por riesgo del desarrollo en el nuevo régimen de daños causados por productos sanitarios defectuosos

Con la aparición de economías basadas en el consumo masivo de bienes, surgió también la necesidad de proteger efectivamente a los consumidores de los daños que la puesta en circulación de productos podría causarles. Desde el punto de vista de la prevención y la reparación de estos daños, los sistemas clásicos de responsabilidad fallaban. A los consumidores les era prácticamente imposible probar la culpa en el diseño o en la fabricación del producto. Además, el fabricante muchas veces se encontraba muy lejos (incluso en otros países) del consumidor final.

Por lo anterior, el derecho del consumo se desarrolló aumentando las listas de responsables por los daños causados por productos (incluyendo vendedores, distribuidores, etc.), y facilitando la posición probatoria de los consumidores mediante la introducción de presunciones de culpa e, incluso, de regímenes de responsabilidad sin culpa (objetivos).

En Chile, la regulación del consumo no contempla un régimen de responsabilidad por productos defectuosos. Sin embargo, recientemente se han dictado normas específicas sobre "productos sanitarios defectuosos", y esta regulación reviste una importancia radical en el tema que nos interesa, pues la cura del covid-19 parece pasar por la elaboración de un nuevo medicamento o la experimentación con otros ya existentes, y la normativa referida parece haber excluido la posibilidad de hacer valer la excusa liberatoria por riesgos del desarrollo.
En efecto, la Ley No20.850 de 2015 (conocida como Ley Ricarte Soto) insertó un nuevo título al libro IV del Código Sanitario, regulando la responsabilidad por daños asociados a "productos sanitarios". Entre éstos se encuentran productos farmacéuticos, productos alimenticios y otros elementos de uso médicos; y estos últimos comprenden (con algunas excepciones) instrumentos, aparatos, dispositivos y otros artículos o elementos destinados al diagnóstico, prevención y tratamiento de enfermedades de seres humanos, así como al reemplazo o modificación de sus anatomías (art. 111).

La ley considera "producto sanitario defectuoso" a "aquél que no ofrezca la seguridad suficiente, teniendo en cuenta todas las circunstancias ligadas al producto y, especialmente, su presentación y el uso razonablemente previsible" (art. $111 \mathrm{H})$. Como se ha observado, esta definición amplia abarca todas las categorías de defectos que han sido consideradas en el Derecho comparado: los defectos de fabricación (aquí la ley señala expresamente que un producto se considera defectuoso si no ofrece la misma seguridad normalmente ofrecida por los demás ejemplares de la misma serie), los defectos de información (si la presentación no incluye la información necesaria para evitar los daños) y los defectos de diseño o concepción (si en sus inicios el producto fue concebido de un modo que resultaba inseguro y potencialmente dañino) (9).

Se trata de un régimen de responsabilidad estricta u objetiva, en tanto no admite que el demandado se exima "alegando que los daños ocasionados por un producto sanitario se originan de hechos o circunstancias que no se previeron según el estado de los conocimientos científicos o técnicos existentes en el momento de su puesta en circulación o uso" (art. 111K). Si bien la ley no impide esgrimir esta excusa liberatoria respecto de todos los productos consumibles, sí lo hace respecto de todos los productos sanitarios, sean estos medicamentos u otros instrumentos de uso médico que probablemente se utilizaron y se utilizarán en el tratamiento de los pacientes que contrajeron y contraerán la enfermedad producida por el SARS-Cov-2 que apareció el año 2019. 
Por lo anterior, tratándose de daños que puedan vincularse con un producto sanitario defectuoso, los sujetos pasivos de la acción contemplados por la Ley Ricarte Soto (los titulares de los registros o autorizaciones, los fabricantes y los importadores, según corresponda) no podrán valerse de la excusa liberatoria de los riesgos del desarrollo. Aunque esta restricción está hecha de manera general para los titulares de los registros o autorizaciones, fabricantes e importadores, tanto públicos como privados, la remisión que hace el artículo $111 \mathrm{I}$ a la Ley No19.966 plantea dudas sobre la aplicación de este régimen a la CENABAST.

En efecto, la norma referida establece que la CENABAST responderá "conforme a las reglas establecidas en el Título III de la Ley No19.966" que, como vimos, establece un régimen de responsabilidad subjetivo. Si a la CENABAST se le aplica dicho título III, podría plantearse la duda interpretativa de si la aplicación del artículo 41 (que parece incluir una excusa liberatoria por riesgo del desarrollo) se aplica de forma preferente a la norma incluida en el artículo $111 \mathrm{~K}$ que no admite dicha excusa.

\section{Herramientas normativas para tratar una pan- demia}

Como advertimos, además de su novedad, la enfermedad producida por el SARS-Cov-2 presenta la particularidad de haberse transformado muy rápidamente en una pandemia y, por lo mismo, en un problema de salud pública $(10,11)$. Por ello, la autoridad sanitaria (el Ministerio de Salud, MINSAL) ha tomado la administración de la emergencia dictando una serie de normas que buscan proveer formas de tratamiento de la enfermedad y evitar el contagio masivo de la población ${ }^{4}$.

Se ha generado así un nuevo contexto normativo que afectará la lex artis médica. No solo respecto del tratamiento de pacientes que hayan contraído covid-19, sino también del tratamiento de otras patologías. De esta manera, la autoridad sanitaria afectará el estándar de conducta por el que responderán los prestadores individuales o institucionales de salud mientras dure la pandemia, y

\footnotetext{
${ }^{4}$ Una lista de las normas emitidas por el Ministerio de Salud de Chile puede verse en: https://www.gob.cl/coronavirus/documentos/.
}

será la autoridad la responsable por la gestión del riesgo de catástrofe que para la población general supone la pandemia.

\section{La adaptación de la lex artis médica a la situa- ción de pandemia}

Cuando la salud pública reacciona ante una pandemia cambiando el escenario normativo, como ha ocurrido con el covid-19, las nuevas normas no solo afectarán los protocolos de atención de la enfermedad epidémica. Debido a circunstancias como la escasez de recursos o a la necesidad de contener los riesgos asociados a la pandemia, puede afectarse la conducta médica que debe emplearse en el tratamiento de otras patologías. Un buen ejemplo de lo anterior es la resolución del MINSAL que ordena a establecimientos públicos y privados postergar las cirugías electivas cuyo retraso no signifique un riesgo grave para la salud del paciente ${ }^{5}$.

Es importante advertir que el efecto referido solo se mantendrá mientras la enfermedad sea un problema de salud pública. Una vez controlada la pandemia ( $y$ con independencia de que se haya encontrado una cura), la resolución del MINSAL perderá eficacia y el estándar de cuidado o lex artis médica se verá restaurado. A efectos del juicio de responsabilidad, esta idea es clave puesto que permite explicar por qué la jurisprudencia de época prepandémica puede no ser pertinente para evaluar conductas durante la pandemia.

Tan solo por poner un ejemplo, en el caso Quiroz con Servicio de Salud Araucanía, fallado en 2018 por la Corte Suprema, un hombre sufrió la rotura del tendón de Aquiles. Inicialmente se le indicó una cirugía para tratar la lesión, pero finalmente se optó por un procedimiento no quirúrgico. Lamentablemente, este tratamiento no logró que la rotura del tendón sanase, quedando el paciente con una cojera permanente. El tribunal condenó al Servicio de Salud a indemnizar al paciente, pues estimó que "el procedimiento no quirúrgico adoptado a través de la postura de 'yeso bota corta equino' no fue el idóneo (...), teniendo en especial consideración que el diagnóstico previo del especialista en la materia, demostraba la ne-

\footnotetext{
${ }^{5}$ Resolución Exenta No203, de 24 de marzo de 2020, de la Subsecretaría de Salud Pública.
} 
cesidad de una intervención quirúrgica que, en definitiva, no se materializó por la falta de camas en el recinto hospitalario"'.

Si los hechos del caso que acabamos de referir hubiesen ocurrido hoy, se tendría que exonerar de responsabilidad al Servicio de Salud, puesto que, como ya adelantamos, actualmente se encuentran suspendidas las cirugías electivas cuyo retraso no signifique un riesgo grave para la salud del paciente. Por lo anterior, puede decirse que, para el tratamiento de una lesión en el tendón de Aquiles como la que sufrió el señor Quiroz y siempre que se considere que una cojera no es un "riesgo grave para la salud", hoy la lex artis médica ha variado, no siendo exigible la realización de un procedimiento quirúrgico.

Un segundo ejemplo de cómo una pandemia puede cambiar el juicio respecto de determinadas conductas, lo podemos encontrar en aquella jurisprudencia que suele condenar a los Servicios de Salud por los perjuicios que sufren los pacientes por las atenciones que brindan profesionales de la salud que no son especialistas o no tienen la experiencia suficiente. En estos casos, los tribunales han sentenciado que una atención por médicos no especialistas evidencia una falta de servicio del establecimiento asistencial, ya sea por una deficiente distribución de tareas dentro de la institución o por carecer de un adecuado sistema de derivación a otro establecimiento ${ }^{7}$.

Si tales casos ocurriesen hoy se debería tener presente que, en virtud de las facultades extraordinarias que le entrega un estado de emergencia sanitaria, el MINSAL ha dictado normas que permiten la contratación de personal no calificado (estudiantes del área de la salud que se encuentran cursando sus últimos años de estudio) ${ }^{8}$ y de médicos que han obtenido su título en el extranjero sin la necesidad de que sea revalidado y sin que haya rendido el Examen Único de Conocimientos de

\footnotetext{
${ }^{6}$ Corte Suprema, Rol N³7.349-2017.

${ }^{7}$ Fuentealba con Servicios de Salud Talcahuano (Corte Suprema, Rol N²1.599-2017); Villamán con Tiznado y Servicio de Salud Bío Bío (Corte de Apelaciones de Concepción, Rol No917-2007).

Bravo con Ortega y Servicio de Salud Central (Corte Suprema, 4 de octubre de 1984, Rol No23.634).

${ }^{8}$ Decreto Supremo No4, de 5 de enero de 2020, del Ministerio de Salud.
}

Medicina (EUNACOM) ${ }^{9}$. De la implementación de estas medidas de emergencia, que surgen como una forma de afrontar la sobredemanda que implica la pandemia, cabe preguntarse si, en caso de que este personal no calificado causara perjuicios a un paciente, podrían los tribunales concluir que este simple hecho evidencia una falta de servicio o actuar negligente del centro de salud, como se ha concluido de forma consistente por la jurisprudencia prepandémica.

Los ejemplos anteriores muestran que la conducta médica debida durante la emergencia se verá alterada por los actos de la autoridad. Ello debe ser tomado en consideración en los juicios de responsabilidad que se presenten en el futuro. Una cuestión distinta dice relación con la posible variación del "grado de diligencia" con que deben actuar los profesionales de la salud en el contexto de la emergencia. Como ya se analizó, la regla de conducta médica se construye comparando la conducta efectivamente desplegada por el médico con la que hubiese debido desplegar, atendido un juicio de previsibilidad de daños de un buen profesional de la salud. En sentido técnico-jurídico, se trata de la noción de "culpa leve". Pero como en el derecho de daños también se reconoce la categoría de "culpa grave" para juzgar la responsabilidad de personas que se encuentran en situaciones excepcionales, cabe preguntarse si debería juzgarse la responsabilidad de los médicos que actúan en el contexto de la emergencia sanitaria con base en este grado de negligencia, e incluso más, si debería siquiera enjuiciárseles.

En el contexto de este debate, el gobernador del Estado de Illinois (EE.UU.) promulgó una regla especial para prestadores individuales e institucionales de salud. En particular, decretó que ellos serán inmunes a demandas de responsabilidad civil por eventuales lesiones o muertes que puedan causar con ocasión de su participación en la emergencia sanitaria, salvo que se acredite que actuaron con culpa grave o dolo ("gross negligence or willful misconduct") ${ }^{10}$. En igual sentido, el European Law Institute ha promovido que los Estados

\footnotetext{
${ }^{9}$ Decreto Supremo No6, de 6 de marzo de 2020, del Ministerio de Salud.

${ }^{10}$ Executive Order 2020-19, de 1 de abril de 2020. Disponible en: https://www2.illinois.gov/Pages/Executive-Orders/ExecutiveOrder2020-19.aspx.
} 
adopten políticas para asegurar que los prestadores de salud no sean condenados por los efectos adversos de sus intervenciones relacionadas con el covid-19, salvo que actúen, al menos, con culpa grave ("gross negligence") 11 .

$\mathrm{Al}$ respecto, conviene tener presente que la tesis de la responsabilidad médica especial basada en la culpa grave ha sido discutida en diferentes momentos de la historia, y ha sido progresivamente abandonada por la mayor parte de la doctrina y la jurisprudencia(12). Ello no significa que el juicio de responsabilidad que pueda dirigirse contra los prestadores individuales e institucionales de salud desatienda las especiales circunstancias de incertidumbre y sobredemandada que la emergencia sanitaria impone al ejercicio de la medicina. Lo anterior, porque preguntarse por el estándar general de cuidado de la "culpa leve" es preguntarse por lo que debería haber hecho un modelo medio de profesional de la salud (en abstracto), pero tomando en consideración las circunstancias particulares (externas al sujeto) en que se desarrolló la acción.

Por todo lo hasta aquí dicho, no se ve la necesidad de abogar por un régimen de responsabilidad que "únicamente" reproche las conductas de los prestadores individuales e institucionales cuando no atienden a los pacientes con el cuidado con que aun las personas negligentes tratan la salud propia (art. 44 del Código Civil). Si a ello agregamos que, en nuestro sistema de daños, una modificación como la que se propone necesitaría articularse mediante una reforma legal, creemos que no nos equivocamos al afirmar que lo más probable es que la culpa leve será el criterio con que se juzgará las acciones y omisiones del personal médico en el contexto de la emergencia sanitaria.

\section{La responsabilidad de la autoridad encargada la gestión del riesgo asociado a la pandemia}

Además de los cambios en los protocolos y del necesario ajuste del estándar de cuidado que deban cumplir los prestadores en salud, una epidemia es un hecho natural cuya gestión corresponde, con el debido apoyo de órganos técnicos, a un órgano u autoridad de la administración del Estado. Sin

\footnotetext{
${ }^{11}$ Las propuestas de este instituto están disponibles, en inglés en: https://www.europeanlawinstitute
}

duda, desde el punto de vista de la seguridad de las personas, el gran peligro que enfrentamos es que la emergencia sanitaria que ha provocado el SARS-CoV-2 se transforme en un "desastre sanitario", por el impacto que la propagación descontrolada de la enfermedad pueda tener en la vida de las personas.

Frente a un escenario de desastre, los Estados disponen de diversos instrumentos como, por ejemplo, fondos públicos de emergencia de seguridad para salir en ayuda de las personas. Pero, adicionalmente, las víctimas de la pandemia y sus familiares también cuentan con las normas que regulan la responsabilidad patrimonial de la administración del Estado para obtener la reparación de los daños patrimoniales y extrapatrimoniales que se puedan asociar al manejo negligente de la crisis.

Desde el punto de vista del derecho de daños, si a una gestión negligente del riesgo asociado a la epidemia pueden vincularse daños, corresponderá imputar la obligación de indemnizar los daños no cubiertos por otros sistemas de protección social al órgano de la administración competente. En casos como el que nos ocupa, podría pensarse que, debido a la duración promedio de un juicio ordinario en Chile (siete años, aproximadamente) y a las dificultades técnicas que implica la prueba de la negligencia y de la relación de causalidad entre los actos de autoridad y los daños, el recurso a la responsabilidad patrimonial será de ultima ratio. Sin embargo, la experiencia que obtuvimos recientemente en un caso analogable (terremoto y tsunami del 27 de febrero de 2010), indica que son altas las probabilidades de que los familiares de las víctimas de la pandemia demanden masivamente la responsabilidad civil del Estado. De ahí que conviene analizar, aunque sea someramente, los elementos de juicio sobre el manejo de la emergencia y el problema del establecimiento de la relación de causalidad entre la conducta negligente y los dańos que a ella se asocien.

Respecto del enjuiciamiento de la actuación de la autoridad en el manejo de la emergencia sanitaria, se debe partir por advertir que el impacto que tiene un fenómeno natural en la vida de las personas no es ajeno a la organización social. Muy por el contrario, el impacto dependerá de la con- 
junción entre el fenómeno natural y el nivel de vulnerabilidad (o exposición al riesgo de desastre) que tenga una sociedad determinada. A su vez, el nivel de vulnerabilidad guardará estrecha relación con el nivel de desarrollo económico del país que se analice, lo que es un importante aspecto al momento de enjuiciar la conducta de los órganos de la administración del Estado destinados a gestionar los riesgos asociados a una pandemia.

La idea anterior es importante, porque sabemos que esta pandemia tendrá efectos nocivos en la vida de las personas, pero hay cierto nivel de nocividad que no será tolerable puesto que "depende" de las acciones u omisiones que la autoridad realice durante la misma. Como expresara San Martín, a propósito de los casos relacionados con el 27 de febrero de 2010, "esta conclusión (...) es la que permite atribuir responsabilidad — de carácter civil, penal o administrativa - por la ocurrencia de un desastre, de lo contrario, si fueran inevitables, caerían en la categoría del caso fortuito o fuerza mayor"(13:1151).

En concreto, si la amenaza de pandemia está determinada por las medidas que se pueden tomar para disminuir el nivel de exposición de la población, habrá que evaluar qué políticas se tomaron y la oportunidad de éstas. Por ejemplo, tendremos que preguntarnos si fueron medidas apropiadas y oportunas para evitar la expansión del virus: i) la obligación de hacer una declaración jurada que se impuso a las personas que venían viajando desde el extranjero en lugar de ordenarles hacer cuarentena ${ }^{12}$; ii) el plan de retorno seguro y de nueva normalidad que impulsó el gobierno a finales del mes de abril del 2020, o iii) encargar la trazabilidad de los casos con covid-19 a la atención primaria (recién) a partir de junio de 2020.

Respecto del establecimiento de la relación de causalidad en el caso que nos ocupa, se presenta un problema de muy difícil solución. Y es que, según el entendimiento estándar de la doctrina y la jurisprudencia de nuestro medio, cada una de las personas que pretenda una indemnización deberá acreditar que entre el daño que invoque y el acto u omisión de la autoridad que se sindique

\footnotetext{
${ }^{12}$ Resolución Exenta No108, de 27 de febrero de 2020, del Ministro de Salud. Disponible en: https://www.minsal.cl/wp-content/ uploads/2020/02/1734494-covid-Declaracion.pdf.
}

media una adecuada relación de causalidad. Por ejemplo, en el caso de muerte de un familiar por coronavirus, habrá que probar que si no se hubiese realizado una u otra acción u omisión por parte de la autoridad su familiar no se hubiera infectado y, además, no hubiera fallecido.

De lo anterior pudiera pensarse que, prima facie, las demandas contra el Estado por actos u omisiones de la autoridad en el manejo de la emergencia no debieran prosperar. Sin embargo, la reciente experiencia de los casos asociados al terremoto nuevamente muestra lo contrario. Para salvar las dificultades probatorias del nexo causal, que en el caso del tsunami se presentaban de manera análoga a las que se presentan en el caso de que nos ocupamos (había que demostrar que de haberse efectuado el aviso las personas estas no hubiesen fallecido), se recurrió a una noción que en los últimos años viene anidando en la jurisprudencia de la sala tercera de la Corte Suprema: la "pérdida de una chance" de sanar o sobrevivir.

En los términos más básicos posibles, la teoría de la "pérdida de la chance" postula que si no es posible acreditar (con certeza) que el acto u omisión de que se trate causó la muerte de la víctima, pero sí se puede dar por acreditado que lo privó de una probabilidad (cierta) de salvarse, esta pérdida cierta de probabilidades debe ser indemnizada(14-17). Aunque en nuestro medio la teoría aún se encuentra en un estado de desarrollo embrionario, una reciente aplicación jurisprudencial de la misma puede verse en Escalona y otros con Fisco de Chile. En el caso, conociendo de un recurso de casación que precisamente cuestionaba el establecimiento de la relación de causalidad, la Corte Suprema sostuvo que el juez de instancia habría aplicado correctamente la teoría de la pérdida de la chance, puntualizando que no se habría dado por acreditado el vínculo causal entre la falta de aviso y la muerte de la víctima, sino entre la falta de aviso y la "(...) pérdida de la oportunidad de alejarse de las zonas de riesgos antes de la llegada de las olas que determinan la muerte o afectación de las personas" ${ }^{\prime 3}$.

Como se ve, la pregunta por la responsabilidad de la autoridad encargada de gestionar los riesgos asociados a la pandemia presenta espinosos pro-

${ }^{13}$ Corte Suprema, Rol No12169-2017, considerando $13^{\circ}$. 
blemas. Por ello, cabe preguntarse si el derecho de la responsabilidad civil es el instrumento óptimo para cubrir este tipo de acontecimientos o si, por el contrario, son otros los instrumentos normativos los que deberían emplearse. La pregunta es sin duda atingente, pero, mientras ese debate se desarrolla, nos parece que el sistema de responsabilidad patrimonial seguirá siendo la última línea de protección del ciudadano y que, por lo mismo, muchos de los casos relacionados con la pandemia se resolverán, como pasó con los casos del tsuna$\mathrm{mi}$, con las viejas normas de la responsabilidad civil que hoy, sintomáticamente, son rebautizadas como derecho de daños.

\section{Conclusiones}

El SARS-Cov-2 ha puesto en evidencia que una enfermedad puede tensionar el régimen de responsabilidad médica desde dos perspectivas.

Por una parte, una enfermedad, cuando es nueva o inédita, tensiona el régimen de responsabilidad obligando al sistema de salud a actuar en un contexto en el que la posibilidad de controlar o prever las consecuencias es limitada. Ante el riesgo de actuar frente a una enfermedad desconocida, el Derecho protege a los prestadores de salud al sujetar su responsabilidad a un régimen de responsabilidad por culpa. Bajo este régimen, la responsabilidad de aquellos prestadores se encuentra restringida a lo previsible, excluyendo aquellos dańos que no se hubieran podido prever o evitar según el estado de los conocimientos de la ciencia. Esta eximente de responsabilidad se encuentra explícitamente reconocida en el artículo 41 de la Ley No19.966, para los órganos de la administración del Estado. Sin embargo, cuando se trata de daños que provienen de productos sanitarios defectuosos, la cuestión cambia. Respecto de esos bienes, tanto los titulares de los registros sanitarios como sus fabricantes e importadores responderán incluso de aquellos daños que no se hubieran podido prever o evitar según el estado de los conocimientos de la ciencia.

Por otra parte, cuando una enfermedad deviene en pandemia, aquella pasa a ser un problema de salud pública que suele traer aparejado un cambio en el escenario normativo de la actividad médico-sanitaria. Esto incide en la imputación de responsabilidad por los daños que puedan ocurrir durante una pandemia. En el caso del covid-19, vimos que las nuevas normas, antes que afectar el estándar de cuidado abstracto de prestadores individuales o institucionales, están redefiniendo los protocolos de conducta de la actividad sanitaria. Cuestión que alcanza no solo al tratamiento de la enfermedad epidémica, sino también de otras patologías. Esto obliga a ser cuidadosos en el uso de la jurisprudencia de época prepandémica a los casos que acaezcan durante la pandemia.

Por último, el nuevo escenario normativo provocado por la pandemia obliga a diferenciar la responsabilidad de los prestadores individuales e institucionales de salud de la que pueda corresponder a la autoridad encargada de controlar la emergencia. Responsabilidad última que surge cuando hay culpa de la autoridad (Estado) en la gestión del riesgo conforme a los medios económicos y administrativos disponibles. En un eventual escenario en que se persiga la responsabilidad del Estado en el manejo de la pandemia del covid-19, la teoría de "la pérdida de la chance" seguramente será invocada por los tribunales para superar las dificultades que supone acreditar el nexo causal entre el daño sufrido y la acción u omisión de la autoridad. 


\section{Referencias}

1. John Hopkins University. Maps and Trends Mortality Analyses [Internet]. [citado 15 jul 2020] Disponible en: https:// coronavirus.jhu.edu/data/mortality.

2. Cárdenas H, Moreno J. Responsabilidad médica: estándares jurisprudenciales de la falta de servicio. Santiago de Chile: Legal Publishing Chile; 2011.

3. Valdivia JM. La culpa médica en la responsabilidad de los hospitales públicos. Rev. Med. Chile 2018; 146(9): 10281032. DOI: http://dx.doi.org/10.4067/s0034-98872018000901028.

4. Le Roy M. L'évaluation du préjudice corporel. Paris: Éditions Litec; 1996.

5. Barros E. Tratado de responsabilidad extracontractual. Santiago de Chile: Editorial Jurídica de Chile; 2006.

6. Pizarro C. Controversias jurisprudenciales de la responsabilidad de los servicios públicos de salud. Cuadernos de Análisis Jurídico, Colección Derecho Privado 2010; VI (Responsabilidad médica): 187-198.

7. Coderch P, Puig A. Riesgos de desarrollo y demarcación judicial de la buena ciencia. Anuario de derecho civil 2008; 61(1); 5-56. Disponible en: https://dialnet.unirioja.es/servlet/articulo?codigo=2732349;

8. Mantilla F, Ternera F. El riesgo de desarrollo en la responsabilidad por productos del derecho colombiano. Ius et Praxis 2014; 20(1): 39-66.

9. Corral H. El primer régimen legal chileno de responsabilidad por productos: daños por defectos de los productos sanitarios. Doctrina y jurisprudencia penal 2019; 37: 3-17.

10. Dawson A. Resetting the parameters. In: Dawson A, editor. Public Health Ethics: Key Concepts and Issues in Policy and Practice. Cambridge: Cambridge University Press; 2011: 1-19.

11. Lolas F. Public health and social justice. Toward ethical sustainability in healthcare and research. Acta Bioethica 2003; 9(2): 189-194. Disponible en: https://actabioethica.uchile.cl/index.php/AB/article/view/16799/17496.

12. Bueres A. Responsabilidad civil de los médicos. Buenos Aires: Hammurabi, $3^{\mathrm{a}}$ ed.; 2006: 51 y ss.

13. San Martín L. Desastres Naturales y responsabilidad civil: posible concurso causal entre actividad humana y fenómeno natural. En Gómez et al. Estudios de Derecho Civil XIV. Santiago de Chile: Thomson Reuters; 2019: 1149-1166.

14. Ríos E, Silva R. Responsabilidad Civil por la Pérdida de la Oportunidad. Santiago de Chile: Editorial Jurídica; 2014.

15. San Martín L. Desastres Naturales y responsabilidad civil: Identificación de los desafíos que presentan esta categoría de hechos dañinos. Revista de Derecho (Valdivia) 2019; 32(2): 131.

16. Tapia M. Pérdida de la chance: ¿un perjuicio reparable en Chile?: En Elorriaga (coord.) Estudios de Derecho Civil VII. Santiago de Chile: Legal Publishing; 2012: 645-674.

17. Cárdenas H. La pérdida de la chance en la reciente jurisprudencia médica. En Gómez et al. Estudios de Derecho Civil XIV. Santiago de Chile: Thomson Reuters; 2019: 1027-1039.

Recibido: 16 de julio de 2020

Aceptado: 2 de agosto de 2020 